\title{
Editorial: The January 2022 cover paper
}

\author{
C. Barry Carter $^{1, *}$ (D) \\ ${ }^{1}$ Department of Chemical and Biomolecular Engineering, University of Connecticut, Storrs, CT 06239, USA
}

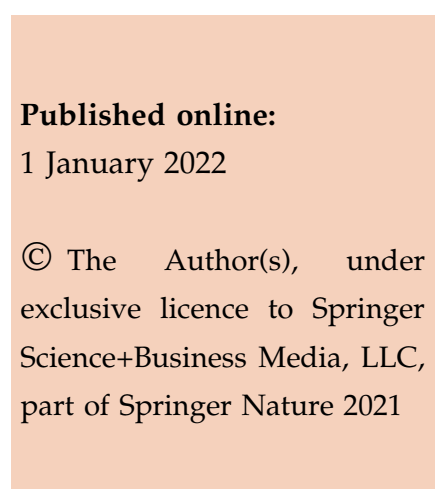

Beginning January 2022, the Journal of Materials Science will have a monthly cover illustration taken from an issue of the journal published in the previous 2 months. The first selection is from a super work by Pinate et al. [1] combining EBSD and microscopy to study the incorporation of particles into a composite layer during electrodeposition. The properties of the deposited layers are measured by indentation. The paper was handled by our Editor Yaroslava Yingling and was included in a Topical Collection with other papers on 'chemical routes to materials'; it could also have been included in the 'composites and nanocomposites' Topical Collection. This choice illustrates one of the classic challenges for a multidisciplinary journal: Producing the material is of course essential, characterization of the material is key so that the authors could understand why the mechanical properties changed, but the new advance was made by modifying the electrochemical deposition of the material. The paper clearly shows that "the addition of submicron-size particles caused a change in the grain growth from columnar to equiaxial" and relates this change in microstructure to the measured increase in the microhardness of the deposited composite layers. So the paper is a nice example of the Tetrahedron of Materials Science (processing, structure, properties and performance).

The paper is 14 published pages long, which is the average length for JMS. (We favor full archival papers.) As is the case for all papers published in JMS (OA or not) it has color throughout-both in the hard copy and the pdf. This paper was published Open Access, but it does also have a SharedIt link like all articles in JMS (https://rdcu.be/cClUF); all papers published in JMS are free-to-read using the SharedIt link from the moment they appear online.

Address correspondence to E-mail: cbcarter@gmail.com 


\section{Reference}

[1] Pinate S, Eriksson F, Leisne P, Zanella C (2021) Effects of SiC particles codeposition and ultrasound agitation on the electrocrystallisation of nickel-based composite coatings. J Mater Sci 56:18463-18476. https://doi.org/10.1007/s10853-021-06 $483-\mathrm{z}$
Publisher's Note Springer Nature remains neutral with regard to jurisdictional claims in published maps and institutional affiliations. 